\title{
Respiratory function changes after asbestos pleurisy
}

\author{
P H WRIGHT, A HANSON, L KREEL, AND L H CAPEL
}

From the Cardiothoracic Institute, London Chest Hospital, East Ham Chest Clinic, London, and the Division of Radiology, Clinical Research Centre, Northwick Park Hospital, Harrow

ABSTRACT Six patients with radiographic evidence of diffuse pleural thickening after industrial asbestos exposure are described. Five had computed tomography of the thorax. All the scans showed marked circumferential pleural thickening often with calcification, and four showed no significant evidence of intrapulmonary fibrosis (asbestosis). Lung function testing showed reduction of the inspiratory capacity and the single-breath carbon monoxide transfer factor (TLCO). The transfer coefficient, calculated as the TLco divided by the alveolar volume determined by helium dilution during the measurement of TLCO, was increased. Pseudo-static compliance curves showed markedly more negative intrapleural pressures at all lung volumes than found in normal people. These results suggest that the circumferential pleural thickening was preventing normal lung expansion despite abnormally great distending pressures. The pattern of lung function tests is sufficiently distinctive for it to be recognised in clinical practice, and suggests that the lungs are held rigidly within an abnormal pleura. The pleural thickening in our patients may have been related to the condition described as "benign asbestos pleurisy" rather than the interstitial fibrosis of asbestosis.

Malignant pleural effusion associated with mesothelioma or bronchial carcinoma is a recognised complication of asbestos exposure. Pleural effusions without obvious tumour among both asbestos workers and ex-workers were first reported by Eisenstadt. ${ }^{1}$ Originally called "asbestos pleurisy" the condition was later called "benign asbestos pleurisy,"2 although one of the first four reported patients developed a pleural mesothelioma 10 years after his effusion first appeared, and another after 12 years. Further cases were subsequently reported ${ }^{3-8}$ and the clinical features were recognised (table 1). Diagnostic thoracotomy was

Table 1 Summary of clinical features of benign asbestos pleurisy

1 Subacute or chronic course with pleurisy

2 Tends to recur

3 Exacerbations are usually unilateral but may affect either side

4 Pleural fluid shows no diagnostic features

5 Few asbestos fibres can be found in pleural biopsies

6 The subpleural lung usually shows alveolitis

7 Many asbestos fibres can be found in the subpleural lung

8 The subjects are probably more likely to develop asbestosis and mesothelioma than unaffected workers necessary in many of these early cases, and operation notes recorded the presence of marked visceral pleural thickening.

Radiographic surveys have shown a greater prevalence of pleural thickening (even excluding hyaline and calcified pleural plaques) among asbestos workers than among the general population. ${ }^{910}$ This thickening has been shown to be associated with a reduction of the vital capacity, total lung capacity, and the single-breath carbon monoxide transfer factor. ${ }^{11-13}$

The case reports of asbestos pleurisy give insufficient data to assess the degree of any residual functional impairment. The surveys based on radiographic appearances show statistically significant but small defects of lung function among grouped subjects with pleural thickening. This paper represents a systematic attempt to assess and analyse lung function in a selected group of asbestos workers with marked diffuse pleural thickening.

\section{Methods}

Reviewing cases of asbestos-related disease seen at East Ham Chest Clinic one of us (AH) noted that four of some 70 patients showed radiographic 
evidence of marked pleural thickening. A review of the records of the lung function laboratory of the London Chest Hospital revealed two more similar cases referred from other consultants.

The clinic notes and radiographs of the six patients were reviewed and details obtained of their industrial exposure, and the course of their lung disease. All the patients then attended for lung function testing. All had determinations of forced expiratory volume in the first second $\left(F_{1}\right)$, forced expiratory vital capacity (FVC), and vital capacity (VC). The forced expiratory volume in the first second as a percentage of the forced expiratory vital capacity (FEV\%) was calculated. The single-breath carbon monoxide transfer factor was measured with a Resparameter (PK Morgan, Chatham); from this measurement the transfer factor (TLCO) was obtained, also the alveolar volume measured by helium dilution during the measurement of transfer factor ( $\mathrm{Va})$ and so the transfer coefficient (Kco) obtained as Tuco/Va. Further lung function tests were performed in some patients. Lung volumes were measured in a constant-volume body plethysmograph. Pseudostatic lung compliance curves were also obtained. After passage of a $4 \mathrm{ml}$ oesophageal balloon the patients were instructed to expire slowly from full inspiration, so that the expiratory flow rate did not exceed $0.51 \mathrm{~s}^{-1}$. The pressure difference between the oesophageal balloon and the mouth was displayed on one channel of an $\mathrm{X}-\mathrm{Y}$ oscilloscope, while the expired volume measured from an Ohio 850 spirometer was displayed on the other. A series of breaths was observed and the traces photographed with a Polaroid camera. When similar traces were repeatedly obtained a characteristic one was selected for analysis. The static compliance (Cstat) was obtained by measuring the slope of the line joining points on the compliance curve at FRC and 0.51 above FRC. The specific compliance (sC) was obtained by dividing Cstat by the measured lung volume. The lung function test results were expressed related to predicted reference values. For the spirometric results, gas transfer values, plethysmograph volumes, Cstat, and $\mathrm{sC}$ the values quoted by Cotes $^{14}$ were used. For the compliance curves mean values and standard deviations were calculated from the extreme ranges of the values reported by Turner et al. ${ }^{15}$

Computed axial tomography (CAT) was performed using a general purpose scanner (EMI 5005). The resulting scans were interpreted by one of us (LK) using criteria derived from scans of patients known to have asbestosis. ${ }^{16}$

\section{Case histories}

PATIENT 1

This man worked as a lagger for 20 years from $\frac{\bar{\infty}}{\bar{D}}$ the age of 16 years, and was heavily exposed to asbestos. At the age of 25 years he attended Eastes Ham Chest Clinic because of transient right-sided $\overrightarrow{0}$ pleurisy with radiographic evidence of a smallpleural reaction. He returned with left-sided pleuritic pain 11 years later. By this time his chest radiograph showed bilateral pleural thickening. $\mathrm{He}$ had abnormal lung function tests (table 2). Now pleural fluid could be obtained when aspiration $-\vec{\omega}$ was attempted. At review eight years later the radiographic changes and lung function tests had응 worsened (fig 1, table 2). Computed axial tomog- raphy scanning showed circumferential pleural thickening most marked over the middle and? lower lobes (fig 2). Pleural thickening was visible along the mediastinum and over the right heart border. There were no significant pulmonaryo changes and there was a normal gravity dependent. gradient of perfusion. This gradient is lost in the

Table 2 Lung function of patient 1

\begin{tabular}{lcc}
\hline & $\%$ predicted & \\
\cline { 2 - 3 } Test & Age 37 yr & Age 45 yr \\
\hline FEV 1 & 68 & 59 \\
FEV $\%$ & 105 & 97 \\
VC & 71 & 65 \\
TLCo & - & 71 \\
KCO & - & 125 \\
\hline
\end{tabular}

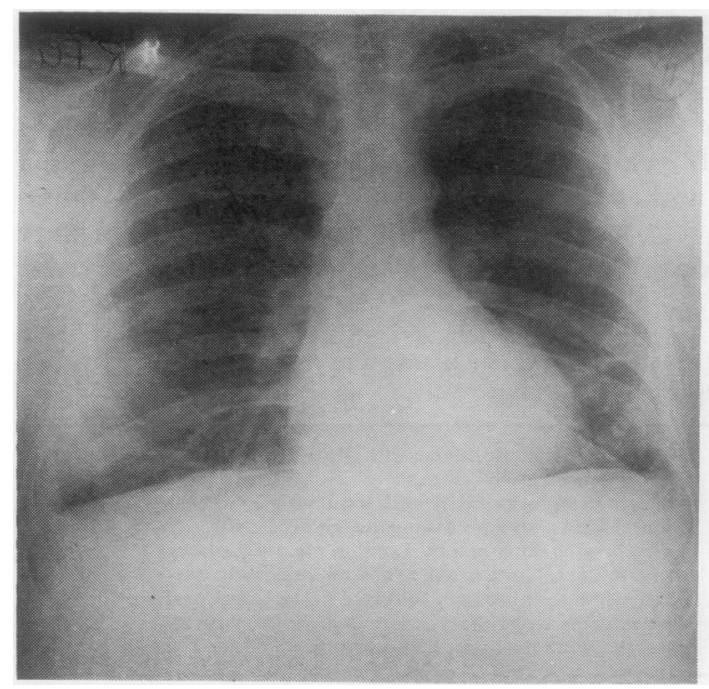

Fig 1 Chest radiograph of patient 1 at age 44 years, 19 years after first pleurisy, showing bilateral pleural thickening. 
presence of the interstitial fibrosis of asbestosis. ${ }^{16}$

The patient continues to smoke 40 cigarettes a day. He has never had finger clubbing or lung crackles. He is now dyspnoeic on hurrying up stairs or hills.

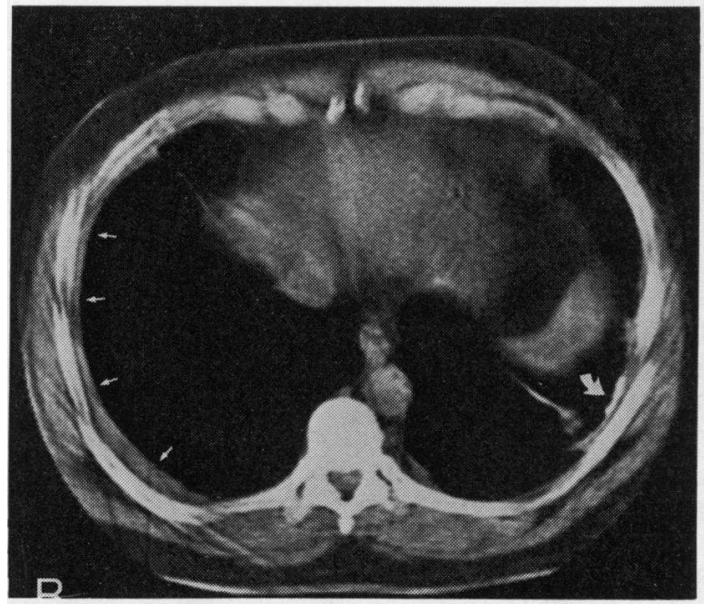

(a)

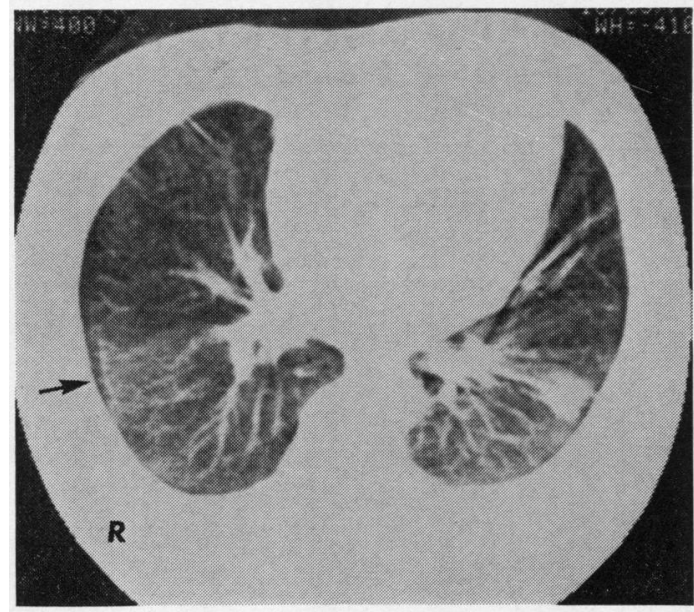

(b)

Fig 2 Transverse computed tomogram of the lower zone of the chest of case 1. (a) Chest wall reveals circumferential pleural thickening lying inside the rib shadows on the right side of the chest. The small arrows indicate the pleural thickening and there are a few thick basal bands. The larger arrow indicates a calcified pleural plaque which was not seen on the plain radiograph. (b) The lung with minimal subpleural fibrosis on the right (arrow), and some pulmonary reaction on the left associated with thickening of the fissure. Vessels are more prominent dorsally indicating a gravity dependent gradient of perfusion.
PATIENT 2

This man worked as a wood machinist in a firm making car batteries from the age of 14 to 65 years. Although he never handled asbestos himself the whole factory was filled with asbestos dust from an adjoining shop where Dagenite was made from asbestos for the battery cases. He first attended East Ham Chest Clinic when aged 60 years, with complaints of exertional dyspnoea and angina. His chest radiograph showed cardiac enlargement and bilateral pleural thickening which was sufficiently dense to obscure the lung fields. Over the next nine years the pleural shadowing increased and lung function deteriorated (table 3 ). He has no finger clubbing but a few late inspiratory crackles were heard at the right base in 1969; these have increased a little since and crackles have appeared at the left base. Computed axial tomography scanning showed bilateral circumferential pleural thickening with almost complete encasement of the left lung, and to a lesser extent the right. There were no significant pulmonary changes, and there was a gravitydependent perfusion gradient. He continues to smoke $2 \mathrm{oz}$ tobacco a week as rolled cigarettes. He cannot walk a quarter of a mile without stopping, but this is because of angina rather than dyspnoea.

Table 3 Lung function of patient 2

\begin{tabular}{|c|c|c|c|}
\hline \multirow[b]{2}{*}{ Test } & \multicolumn{3}{|c|}{$(\%$ predicted $)$} \\
\hline & Age $60 \mathrm{yr}$ & Age $65 y r$ & Age $69 \mathrm{yr}$ \\
\hline $\begin{array}{l}\text { FEV } 1 \\
\text { FEV\% } \\
\text { VC } \\
\text { TLCO } \\
\text { KCO }\end{array}$ & $\begin{array}{r}72 \\
104 \\
73 \\
77 \\
131\end{array}$ & $\begin{array}{r}69 \\
91 \\
67 \\
63 \\
123\end{array}$ & $\begin{array}{r}53 \\
104 \\
54 \\
56 \\
128\end{array}$ \\
\hline
\end{tabular}

\section{PATIENT 3}

This man worked between the ages of 14 and 18 years as a boiler scaler and assistant stoker. From age 18 to 25 years he was a clerk. He then became a process worker in an asbestos factory until it closed 20 years later. During these years he was exposed to asbestos. He has had no further asbestos exposure. He first attended East Ham Chest Clinic at age 36 years with pneumonia of the right lower lobe. Minimal radiographic evidence of bilateral pleural thickening was noted, which has increased slowly since. Finger clubbing was first noted at age 51 years, late inspiratory crackles at age 53 years, and dyspnoea on stairs and hills at age 55 years. He continues to smoke four cigarettes daily. Computed axial tomography scans showed marked pleural thickening on both sides. There 
was minimal calcification of the plaques. Pulmonary changes of asbestosis were also seen and a perfusion gradient was not found.

\section{PATIENT 4}

This man has always worked as a blacksmith and welder. Between the age of 17 and 27 years he worked for a farrier, and then until the age of 39 years as a welder in a steel foundry. Welding rods have been coated with asbestos ${ }^{17} 18$ though the mere use of asbestos-coated electrodes does not produce asbestosis. Since then he has worked in the foundry of a car manufacturer. A routine chest radiograph taken when he joined the car manufacturer showed left pleural thickening. Eight years later there was bilateral shadowing and he was referred to East Ham Chest Clinic. Computed axial tomography scans showed bilateral pleural thickening which was almost circumferential. There were some bullae in the left upper lobe and at the left base with a few bands of interstitial fibrosis, but there was no loss of the perfusion gradient. He continues to smoke 30 cigarettes a day; there are no lung crackles or finger clubbing. He is just dyspnoeic if he hurries on level ground.

\section{PATIENT 5}

This man worked for six months at the age of 21 years grinding and bagging asbestos fibre, with consequent heavy exposure; masks were available though not usually worn. He developed dyspepsia at the age of 47 years, and during a barium meal examination was noted to have bilateral basal shadowing caused by pleural thickening. He smokes 40 cigarettes a day; there are no lung crackles or finger clubbing. Computed axial tomography scans showed multiple calcified pleural plaques extending on to the diaphragm. There was a suggestion of early interstitial fibrosis of asbestosis, but the gravity dependence of perfusion was normal. $\mathrm{He}$ is dyspnoeic hurrying up stairs and hills.

\section{PATIENT 6}

This man has worked since the age of 21 years in a dockyard. Between the ages of 21 and 24 years he was a fitter, from age 24 to 48 years a lagger, and has been a clerk since. He has had regular chest radiographs since the age of 35 years. At the age of 37 years he was said to have had a myocardial infarct and pneumonia. His next routine chest radiograph shortly after showed left-sided pleural thickening. Minimal right-sided changes appeared two years later. There has been minimal worsening over the next 10 years. $\mathrm{He} \stackrel{\overrightarrow{7}}{\stackrel{\vec{f}}{0}}$ has no finger clubbing but a few late inspiratory crackles are present at the left base. He continues $\frac{\bar{c}}{\bar{*}}$ to smoke cigarettes. He cannot hurry on level ground without dyspnoea.

\section{Results}

The results of the spirometric tests and TLco) are shown in table 4. There was a significant reduction in VC among our patients compared with $\times$ the predicted values. There was an associated fallo in the $\mathrm{FEV}_{1}$ but the FEV\% was normal. The TLCo was significantly reduced, but the Kco was $\omega$ significantly increased. Results of further lungo function tests are given in table 5. The loss of VC was the result of a reduction of inspiratory capacity, since both FRC and RV were within? normal limits. The pseudo-static compliance curves are shown plotted individually with two standard deviations either side of the predicted ${ }_{\infty}$ reference values shown as a shaded area. In fig 3. the curves are plotted against the percentage of achieved TLC, and in fig 4 against the percentages of predicted TLC. In both graphs the curves of

Table 4 Routine lung function tests (six subjects, $\%$ predicted values)

\begin{tabular}{lllllll}
\hline & $F E V_{1}$ & $F E V \%$ & $V C$ & TLCo & KCo \\
\hline Mean & 62 & 96 & 69 & 70 & 118 \\
Range & $59-72$ & $92-110$ & $65-78$ & $56-78$ & $102-131$ \\
p $<$ & 0.001 & NS & 0.001 & 0.005 & 0.025 \\
\hline
\end{tabular}

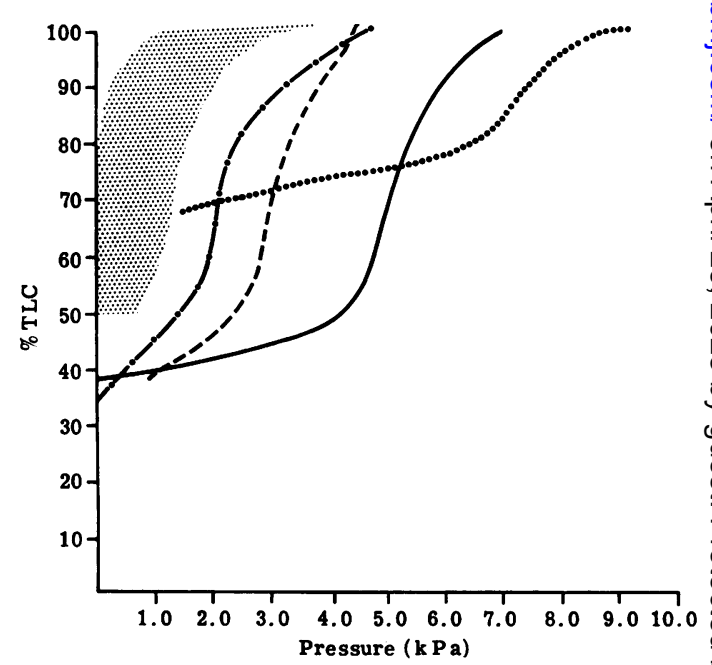

Fig 3 Pressure-volume curves in four subjects. Stippled area represents normal range. 
Table 5 Further lung function tests (four subjects, $\%$ predicted values)

\begin{tabular}{llllll}
\hline & $T L C$ & $R V$ & $F R C$ & $C s t a t$ & $s C$ \\
\hline Mean & 64 & 56 & 71 & 40 & 34 \\
Range & $56-71$ & $17-88$ & $45-92$ & $5-55$ & $5-47$ \\
p $<$ & 0.02 & NS & NS & 0.05 & 0.02 \\
\hline
\end{tabular}

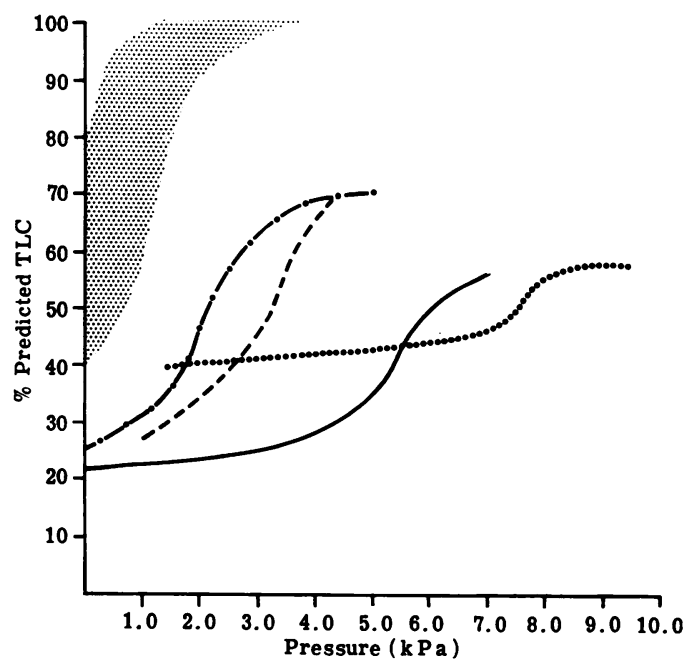

Fig 4 Pressure-volume curves in four subjects, volume as percent of predicted TLC. Stippled area represents normal range.

our patients clearly lie outside the normal range, although the abnormality is more marked in fig 4 which also shows the reduction of TLC. The derived measurements of lung compliance are given in table 5 .

\section{Discussion}

There has been disagreement as to whether visceral pleural thickening associated with asbestos exposure should be regarded as a feature of asbestosis or as a separate disorder. ${ }^{1920}$ The cases we report suggest that severe pleural thickening, sufficient to cause marked loss of lung function and dyspnoea, can occur in asbestos workers without detectable intrapulmonary fibrosis. In two of our patients radiographic evidence of pleural thickening appeared after illness diagnosed as chest infections at the time but, in retrospect, more likely to have been episodes of "benign asbestos pleurisy." In three of the patients progressive pleural thickening occurred without acute episodes, though one of the three had had acute pleurisy. This suggests that although significant pleural thickening can follow benign asbestos pleurisy in some cases, in others the pleurisy may be asymptomatic. If this thickening causes loss of lung function with resulting symptoms it should, perhaps, be accepted that disability meriting compensation could arise. Our findings provide evidence that such disability can occur without asbestosis as it is currently legally defined. The absence of such evidence prevented the Industrial Injuries Advisory Council from recommending a change in the definition of asbestosis more positively in $1973 .{ }^{21}$

The lung function test results of our patients differ from those found in asbestosis with intrapulmonary fibrosis. ${ }^{17}$ In the routine tests the main difference is the high Kco. A raised Kco with low lung volumes may be found if normal subjects take a submaximal inspiration during the measurement of TLco. ${ }^{22}$ The further lung function tests we performed showed a significant difference between our patients and normal subjects taking submaximal breaths. The compliance curves of our subjects were grossly abnormal, and so were their measurements of Cstat and sC. There must, of course, be some doubt as to the exact significance of oesophageal pressure recordings in the presence of gross pleural disease with possible pleural symphysis. Nevertheless if our recordings reflect pleural pressure they are markedly more negative than results from normal subjects. If it is accepted that pleural pressure is abnormally negative, and since we have demonstrated gross pleural thickening without significant lung disease, it may be suggested that the thick pleura investing the lung rendered it more resistant to applied thoracic and diaphragmatic pressures. Hence more negative pressures must be applied for a given change in lung volume, and if these cannot be produced when the disease becomes gross, inspiratory capacity falls. The high Kco might then reflect the relative normality of the encased lung, and so support the absence of significant intrapulmonary fibrosis.

Although this model of the lung function test results in our patients-the squashed or encased lung-is a logical explanation of them, different results have been reported by other workers. Colp and her colleagues ${ }^{23}$ reported abnormally high intrapleural pressures in three patients with presumed pleural restriction. The first of these three patients had a right phrenic crush followed by pneumonectomy, the second had a unilateral malignant pleural effusion and bilateral posttuberculous lung fibrosis, and the third had systemic lupus erythematosus. The first two 
patients clearly had complex problems rather than just pleural disease. Similar results to those from the third patient have been obtained from others with systemic lupus erythematosus; it has been suggested that muscle weakness may be a significant factor. ${ }^{24}$ Our data represent all that is yet available from patients with restrictive pleural disease alone, and we believe that our finding of abnormally negative intrapleural pressures is likely to be characteristic of this condition.

The differentiation of cases of pleural restriction from cases of asbestosis with interstitial fibrosis alone is important clinically because surgery may relieve pleural restriction..$^{25}$ Early surgery may be desirable to prevent secondary changes likely to occur in the affected lung ${ }^{26}$ although improvement may still follow delayed pleurectomy. ${ }^{27}$. In making this differentiation the radiographic changes of marked pleural thickening will usually suggest the diagnosis even though pleural calcification is not usually visible on the routine PA film. A high $\mathrm{Kco}$ in the face of a reduced VC will usually be sufficient confirmation of a "squashed lung" unless other factors could have prevented inspiration. If so a compliance curve will be necessary to seek evidence of abnormally negative intrapleural pressures. Computed axial tomography can be used to display the anatomical appearances with a clarity impossible with routine radiology.

Our thanks are due to Mrs C Hodder and Ms J Jones, to $\mathrm{Dr}$ OR McCarthy and to Surgeon Captain TP Oliver, to Miss M Rehahn, and to the Department of Medical Illustration, Royal Marsden Hospital.

\section{References}

1 Eisenstadt HB. Asbestos pleurisy. Dis Chest 1964; 46:78-81.

2 Eisenstadt HB. Benign asbestos pleurisy JAMA $1965 ; 192: 419-21$.

3 McNulty JC. Asbestos Mining Wittenoom, Western Australia. In: Proceedings First Australian Pneumoconiosis Conference. New South Wales Joint Coal Board, 1968:447-66.

4 Gaensler EA, Kaplan AI. Asbestos pleural effusion. Ann Intern Med 1971; 7:178-91.

5 Sluis-Cremer GK, Webster I. Acute pleurisy in asbestos exposed persons. Environ Res 1972; 5:380-92.

6 Chahinian $\mathrm{Ph}$, Hirsch $\mathrm{A}$, Bignon $\mathrm{J}$ et al. Les pleurésies asbestosiques non tumorales. Rev Fr Mal Resp 1973; 1:5-39.

7 Leménager J, Rousselot P, Le Bouffant L, Bénard Y. Les pleurésies bénignes de l'amiante. Rev Fr Mal Resp 1975; 3:325-42.
8 Nyiredy G. Benigne asbestpleuritis. Prax Pneumolo 1975; 29:166-9.

9 Collins TFB. Pleural reaction associated with asbestos exposure. Br J Radiol 1968; 41:655-61.

10 Anderson HA, Selikoff I. Pleural reactions to 2 environmental agents. Fed Proc 1978; 37:2496- के

11 McDonald JC, Becklake MR, Gibbs GW, McDonald AD, Rossiter CE. The health of $\vec{\omega}$ chrysotile mine and mill workers in Quebec. Arch Environ Health 1974; 28:61-8.

12 Weill $\mathrm{H}$, Jones $\mathrm{R}$. The chest roentgenogram as an epidemiologic tool. Arch Environ Health 1975; 30:435-9.

13 Lumley KPS. Physiological changes in asbestos $\omega$ pleural disease. In: Walton WH, McGovern B,을 eds. Inhaled Particles IV. Oxford: Pergamon Press, 1977: 781-8.

14 Cotes JE. Lung Function. Oxford: Blackwell Scientific Publications, 1975.

15 Turner JM, Mead J, Wohl ME. Elasticity of human lungs in relation to age. J Appl Physiol $\vec{\circ}$ 1968; 25:664-71.

16 Kreel L. Computer tomography in the evaluation. of pulmonary asbestosis. Acta Radiol (Diagn) 1976; 17:405-12.

17 Parkes WR. Occupational Lung Disorders. London: Butterworths, 1974.

18 Hunter DN. The Diseases of Occupations, 5tho ed. London: Hodder and Stoughton, 1975.

19 Becklake MR. Asbestos-related diseases of theo lung and other organs: their epidemiology and implications for clinical practice. Am Rev Respir Dis 1976; 114:187-227.

20 Parkes, WR. Asbestosis. Lancet 1977; 2:1081.

21 Department of Health and Social Security, In dustrial Injuries Advisory Council. Pneumoconiosi and Byssinosis. Cmnd 5443. London: HMSO 1973.

22 Frans A, Francis Ch, Stanescu D, Nemery B Prignot J, Brasseur L. Transfer factor in patients with emphysema and lung fibrosis. Thorax 1978 . 33:539-40.

23 Colp C, Reichel J, Park SS. Severe pleurap restriction: the maximum static pulmonary recoie. pressure as an aid in diagnosis. Chest 1975; 67 N 658-64.

24 Gibson GJ, Edmonds JP, Hughes GRV. Patternई of pulmonary functional abnormality in systemi lupus erythematosus. Clin Sci Mol Med 1976宂 50:24P.

25 Savage T, Fleming HA. Decortication of the lung in tuberculous disease. Thorax 1955; 10 293-308.

26 Gibson GJ, Pride, NB. Lung distensibility. B $J$ Dis Chest 1976; 70:143-84.

27 Petty TL, Filley GF, Mitchell RS. Objective functional improvement by decortication afted twenty years of artificial pneumothorax for pulo monary tuberculosis. Am Rev Respir Dis 1961 84:572-8. 